\title{
MULINUM SPINOSUM Y LA CARNE DE CORDERO: DETECCIÓN DE SU PRESENCIA EN OVINOS VIVOS
}

\author{
MULINUM SPINOSUM AND LAMB MEAT: DETECTING ITS PRESENCE ON LIVE SHEEP \\ Seoane, N.F. ${ }^{1,3}$, Ochoa, J. ${ }^{1}$, Borrelli, L. ${ }^{2}$, Severino, M.E. ${ }^{1}$, Taddeo, H. ${ }^{2}$, Giraudo, C. ${ }^{2}$ \\ y Andrade Gamboa, J. ${ }^{1,3}$
}

${ }^{1}$ CRUB. Universidad Nacional del Comahue. Quintral 1250. Bariloche8400. Argentina. *seoane@cab.cnea.gov.ar ${ }^{2}$ INTA. Estación Experimental Bariloche. Pje Villaverde s/n. Bariloche 8400. Argentina.

${ }^{3}$ CNEA. Centro Atómico Bariloche. Av. Bustillo 9500. Bariloche 8400. Argentina.

\section{PaLABRAS CLAVE ADICIONALES}

Interacciones planta-herbívoro. Terpenos. Calidad de carne. Cordero patagónico.

\section{RESUMEN}

En Patagonia, la ganadería ovina es una de las principales actividades económicas, pero la calidad de la carne de cordero se ve afectada por el sabor desagradable que toma a causa de la ingesta de neneo (Mulinum spinosum (Cav.) Persoon, Apiaceae) que es una planta predominante, y muy accesible para el ganado en primavera-verano. Para detectar los animales afectados antes de su sacrificio, se ensayaron técnicas fitoquímicas en diferentes órganos de la planta y del animal buscando correspondencias. Se estudiaron 2 grupos (uno con neneo como componente de la dieta y el otro no) de 6 animales cada uno a los que se extrajeron muestras de carne, grasa, hígado, orina y sangre. Los compuestos responsables del efecto del neneo pertenecen al grupo de los terpenos/esteroles, el único presente tanto en las flores de neneo, como en la orina de los corderos. Los tejidos animales fueron inadecuados para detectar el neneo siendo la orina el medio más apropiado para ello. Se propone un protocolo con la intención de generar una herramienta que permita desarrollar tecnologías de bajo costo para superar la dificultad, que queda a disposición de investigadores y productores para su puesta a prueba, con el fin de detectar un posible sabor desagradable previo al sacrificio, evitando así la consecuente pérdida económica.

\section{SUMMARY}

In Patagonia, sheep farming constitutes one of

Recibido: 18-3-09. Aceptado: 15-9-09.

\section{AdDitional KeYWORDS}

Plant-herbivore interactions. Terpenes. Meat quality. Patagonian lamb.

the major economic activities, but the quality of lamb meat is seriously affected by a disagreeable taste found in its tissues, derived from the ovine intake of neneo (Mulinum spinosum (Cav.) Persoon, Apiaceae), predominant in grazing lands easily accessed by sheep during the warm seasons. With the aim of detecting the affected animals before their slaughter, phytochemical testing techniques were applied on different organs of the plant and animal accordingly, in order to identify matches. We studied two groups (one had neneo in their diet while the other did not) of six animals each, of which were extracted samples of meat, fat, liver, urine and blood. The compounds responsible for the effect of neneo belong to the terpene/sterol group, the only present in the flowers of neneo as in the urine of lambs. Various animal tissues were inadequate to detect the presence of neneo in lambs, only urine has been identified as the most suitable to examine the metabolites. A protocol, to experiment with it, was proposed, with the aim of generate a useful tool for the development of low-cost technologies. This protocol is available to researchers and producers to put to the test, with the aim of detecting a disagreeable taste in the animals before their slaughter and avoiding the consequent economic loss.

\section{INTRODUCCIÓN}

La calidad de la carne es uno de los determinantes para su consumo, y entre los 
factores que la definen se encuentra el sabor. Para el caso de la carne de cordero, por ejemplo, éste es uno de los principales motivos de rechazo, por encima del precio, la confianza en la sanidad y otras causas (Sánchez et al., 2001). La ausencia de sabores anómalos es uno de los factores que determinan la calidad de un producto cárnico. La naturaleza de la dieta influye fuertemente en la composición de los productos y tejidos animales debido a compuestos específicos que son transferidos directamente desde el alimento al producto final, transformados o producidos por microorganismos del rumen o por el metabolismo del animal (Prache, 2007) principalmente a través de sus efectos en la cantidad y tipo de grasa intramuscular (Wood et al., 1999).

En Patagonia, donde la ganadería ovina es una actividad económica importante, la calidad de la carne de cordero se ve afectada por el sabor desagradable que imprime a los tejidos la ingesta de neneo (Soriano, 1949; Dimitri, 1974), efecto que adquiere una relevancia mayúscula, pues actualmente se da en la región un proceso de diversificación en los sistemas ganaderos tradicionales de obtención de fibras, que tiene a la producción de carne ovina como una de sus alternativas más promisorias. Este proceso enfrenta dos limitantes principales: los bajos índices de producción y la variación en la calidad del producto. Estudios recientes han desarrollado estrategias para mejorar y estabilizar los índices de producción de carne avanzando en la superación del primer limitante (Giraudo et al., 1999; Giraudo et al., 2004), mientras que la variabilidad en la calidad del producto permanece falta de estudios sistemáticos, siendo el neneo uno de los responsables de afectar esta calidad.

El neneo (Mulinum spinosum (Cav.) Persoon (Apiaceae)), es un arbusto espinescente intrincadamente ramoso de hojas tripartitas que generalmente forma matorrales hemisféricos en cojín. Es una planta muy difundida como principal componente de la estepa herbáceo-arbustiva y sobre las lade- ras bajas desde San Juan y Mendoza hasta Santa Cruz en Argentina y desde Coquimbo a Magallanes en Chile, apareciendo a altitudes de 40-1500 m.s.n.m (Constance, 1988). Es la principal arbustiva de disponibilidad primavera-estival cuyos brotes, flores y frutos forman parte importante de la dieta de ovinos y caprinos en la región patagónica (Bonino et al., 1986; Somlo et al., 1981; Bonvissuto y Somlo, 1998) y de la fauna salvaje autóctona o asilvestrada como guanacos (Lama guanicoe) (Bahamonde et al., 1986; Baldi et al., 2004), chinchillón (Lagidium viscacia) (Galende et al., 1998) y ciervo colorado (Cervus elaphus) (Bahamonde et al., 1986).

El exudado resinoso de $M$. spinosum ha sido estudiado en términos generales (Chiessa y Montes, 1962) y trabajos más recientes han revelado la presencia de varios metabolitos principalmente del grupo de los triterpenos/esteroles, tales como $\alpha$ y $\beta$-pineno y limoneno, $\alpha$-tujeno, camfeno, $\delta$ cadineno, spatulenol, acetato de guaiol (van Baren et al., 1997) y los diterpenoides ácido mulin-11,13-dien-20-oico, ácido mulin-11,13dien-17-hidroxi-20-oico (Nicoletti et al., 1996), ácido mulin-11-eno-13- $\alpha, 14-\alpha-$ dihidroxi-20-oico y ácido 12-eno-20-oico (Chiaramello et al., 2003). No obstante, para resolver el problema del neneo desde una óptica fitoquímica es necesario discriminar la presencia de metabolitos en los distintos órganos de la planta, dado que a pesar de que los animales ingieren hojas durante el año, el efecto del neneo sobre el sabor de las carnes se presenta con la aparición de las flores y posteriormente con los frutos (Ochoa et al., 2003). Ochoa et al. (2003) investigaron familias de metabolitos secundarios en hojas, flores y frutos de $M$. spinosum identificando tres grupos de compuestos presentes en flores y frutos pero ausentes en hojas: saponinas, flavonoides y triterpenos/esteroles.

En este trabajo se propone como objetivo identificar la familia de metabolitos secundarios responsable del efecto del neneo 
en las reses, así como también diseñar un protocolo sencillo y económico para detectar in vivo a los animales afectados.

\section{MATERIAL Y MÉTODOS}

Todas las muestras, fueron tomadas en el Campo Experimental INTA Pilcaniyeu $\left(70^{\circ}\right.$ $28^{\prime} 30^{\prime \prime}$ long. O y $41^{\circ} 05^{\prime}$ lat. S) en la Región Sur de la provincia de Río Negro, Argentina. Este lugar se encuentra en el área de sierras y mesetas occidentales de Patagonia (Anchorena, 1978). El clima es mediterráneo continental con inviernos frío-húmedos, veranos cálido-secos y una precipitación media anual de $300 \mathrm{~mm}$ (Monteith, 1970).

El muestreo se realizó durante las temporadas estivales de 2002/2003 y 2003/2004. Se utilizó como técnica exploratoria una batería de ensayos para familias fitoquímicas de metabolitos secundarios. Estos análisis son de carácter cualitativo o semi-cuantitativo y consisten en reacciones químicas con reactivos colorimétricos y de precipitación. Todas las pruebas se realizaron por duplicado sobre muestras vegetales (hojas, flores y frutos de $M$. spinosum) y muestras de corderos Merino (carne, grasa y orina) con y $\sin$ neneo, menores al año (hembras y machos enteros) y sus respectivas madres.

Para la recolección del material vegetal se trazaron al azar cuatro transectas de $50 \mathrm{~m}$. En cada una se cosecharon flores, frutos y hojas de 10 plantas de neneo, con los que se realizó un pool para cada órgano vegetal. El material vegetal fue secado en estufa a $55^{\circ} \mathrm{C}$ durante 72 horas y luego se pulverizó. Las muestras $(25 \mathrm{~g})$ de las distintas partes de la planta fueron sometidas por separado a una extracción sucesiva con solventes de polaridad creciente durante cuatro horas cada uno. Los solventes utilizados fueron hexano, acetato de etilo, metanol y etanol-agua 1:1. El extracto hidroalcohólico de cada muestra fue liofilizado y preparado al $10 \% \mathrm{p} / \mathrm{v}$ para realizar los siguientes análisis: taninos (Montes y Wilkomirsky, 1985 y Sharapin, 2000); saponinas (Farnsworth, 1966 y
Domínguez, 1973); mucílagos (Montes y Wilkomirsky, 1985); compuestos reductores (Sharapin, 2000); cumarinas, antracenósidos, terpenos, flavonoides y antocianinas (Sharapin, 2000) y alcaloides (Domínguez, 1973).

Los resultados se expresan según sus abundancias relativas: negativos (-), positivos $(+)$ y abundantes $(++)$ de acuerdo a la intensidad del color o intensidad del precipitado, según sea el ensayo que se trate.

Como los productores consideran que 15 días es suficiente para que los animales pierdan el sabor a neneo y no existen antecedentes bibliográficos sobre el tema, un grupo de seis animales fue encerrado durante un mes en un mallín (pastizal natural donde no crece Mulinum spinosum) y considerado sin neneo. Los animales con neneo, fueron tomados al azar entre las majadas que pastoreaban en el campo, donde el neneo es uno de los elementos florísticos dominantes. Para confirmar la consistencia de estos grupos con respecto a sus dietas se tomaron muestras de heces a una selección de seis animales de cada grupo y se analizaron individualmente por medio del análisis microhistológico (Williams, 1969; Latour y Sbriller, 1981; Holechek, 1982). Las muestras de heces se tomaron directamente de la cavidad rectal. El resultado de la lectura microscópica se expresó en forma de porcentajes de frecuencia relativa (Holechek y Gross, 1982), informándose los correspondientes a $M$. spinosum. Las diferencias entre los grupos se probaron con un test de Mann-Whitney (Conover, 1980).

Se sacrificaron seis animales de cada grupo. Se obtuvieron muestras de carne (músculo Semimembranosus), grasa (interna perirrenal), hígado y sangre, las cuales se extrajeron de la misma forma que las muestras vegetales. Se registraron características físicas de los extractos hidroalcohólicos a fin de seleccionar los de mejor condición para realizar los ensayos de detección fitoquímica. Una vez seleccionados, se realizaron sobre éstos los mismos métodos de 
detección utilizados en los ensayos vegetales, pero sólo aquellas técnicas que resultaron positivas en al menos uno de los órganos vegetales ensayados anteriormente.

Sobre orina extraída por apnea manual del animal hasta obtener la muestra (método no invasivo), se ensayaron las técnicas fitoquímicas correspondientes a flavonoides, saponinas y triterpenos/esteroles, según fuera sugerido por Ochoa et al. (2003). Para extraer la orina por este método se tumba al animal de costado y se le tapa el hocico con la mano impidiendo su respiración hasta que orine. En la gran mayoría de los casos los ovinos orinan antes de los 30 segundos de apnea sin presentar síntomas de estrés considerable, pero para reducir el mismo se puede incluso liberar antes al animal si éste no orina y tomar la muestra más tarde. Se tomó una muestra de orina por animal.

Durante el verano 2004/2005 se repitió el diseño experimental para lograr un grupo de animales con neneo y otro sin neneo. Se tomaron 6 muestras de orina de cada grupo. Sobre estas muestras se llevó a cabo pruebas piloto de una técnica para detección de terpenos/esteroles diseñada sobre una modificación de la realizada anteriormente siguiendo a Sharapin (2000). La modificación consistió en una reducción en las cantidades utilizadas y una adaptación a mues- tras animales y al problema particular estudiado, con vistas a diseñar un protocolo de trabajo para detectar el efecto del neneo sobre reses vivas (Ochoa y Seoane, 2007). La técnica experimental utilizada tiene tres partes y su procedimiento se muestra en la tabla I.

La técnica experimental (tabla I) se aplicó tres veces con distintas cantidades de muestra. Las cantidades ensayadas fueron 1:10, 1:100 y 1:200 en relación al ensayo original, por lo que el equivalente a cada parte de la técnica fue de $1 ; 0,1$ y $0,05 \mathrm{ml}$ respectivamente. Se detectó la reducción mínima con la cual el ensayo es funcional y se registraron observaciones y resultados para cada punto de la técnica experimental ensayada.

Sobre la base de los resultados obtenidos se diseñó un protocolo para detectar el efecto del neneo in vivo, si bien la fiabilidad de sus resultados a gran escala se encuentra bajo un período de prueba.

\section{RESULTADOS}

PRINCIPIOS QUÍMICOS DEL NENEOQUEAFECTAN LA CALIDAD DE LAS RESES

Los resultados del screening fitoquímico realizado para hojas, flores y frutos de Mulinum spinosum se encuentran resumidos en la tabla II. Para aquellas familias

Tabla I. Técnica experimental para terpenos aplicada a las muestras de orina. (Experimental technique for terpenes applied to urine samples).

\begin{tabular}{cl}
\hline Parte de la técnica & Procedimiento \\
Punto 1 & A 5 partes de orina se le agregan 2 partes de $\mathrm{HCl} 20 \%$ \\
Punto 2 & Se coloca a reflujo por 20 minutos y se adicionan 2 partes de agua \\
Punto 3 & $\begin{array}{l}\text { Se evapora hasta tres partes aproximadamente. Se extrae con } 2 \text { partes de } \\
\text { éter y se aísla el extracto etéreo. Se agrega } 1 \text { parte de cloroformo y } 1 \text { parte } \\
\text { de anhídrido acético. Se mezcla y se agregan } 3 \text { o } 4 \text { gotas de } \mathrm{H}_{2} \mathrm{SO}_{4}(\text { conc) } \\
\text { por las paredes del tubo }\end{array}$
\end{tabular}

En el ensayo original de Sharapin (2000) aplicado a muestras vegetales 1 parte $=10 \mathrm{ml}$. 
fitoquímicas presentes en alguno de los órganos vegetales ensayados, se realizaron las mismas pruebas de detección sobre el tejido animal.

En función de las características físicas de los extractos orgánicos animales, se seleccionaron los extractos de carne y grasa para realizar los ensayos, ya que los correspondientes a hígado y sangre mostraron defectos experimentales graves que tornaron inestable al extracto. Algunos de éstos fueron la formación de precipitados, emulsiones y espuma. Los resultados obtenidos para los ensayos en carne y grasa de corderos con y sin neneo se muestran en la tabla II. Para todos los ensayos las repeticiones realizadas coinciden en sus resultados, a excepción de los casos en los cuales se indica, donde no existe un resultado uniforme.

Los grupos de corderos con y sin neneo se confirmaron mediante análisis microhistológico de sus dietas que revela el porcentaje de Mulinum consumido por cada grupo (figura 1). Los grupos difieren significativamente en sus dietas en cuanto a la cantidad de neneo consumido (test de Mann-Whitney $\mathrm{p}<0,005)$. Además puede verse que la desviación de cada grupo se corresponde con las condiciones experimentales de cada uno, en el grupo sin neneo el ambiente homogéneo del mallín donde $M$. spinosum no crece, ofrece sin embargo alguna cantidad de la planta que podría deberse a un efecto borde alrededor del alambrado. En el grupo con neneo, los animales alimentándose a campo tienen la oportunidad de elegir y la variación individual en cuanto a los hábitos de forrajeo otorgan mayor variabilidad a este grupo.

En los análisis sobre orina de corderos el único ensayo que mostró diferencias entre animales con y sin neneo fue el correspondiente a los triterpenos/esteroles (tabla III), por lo que la sustancia o el grupo de sustancias que provoca el efecto del neneo en las reses, se encuentra metabolizada de alguna forma en la orina de los animales que lo consumen y pertenece al grupo de los terpenos.

Con respecto al procedimiento realizado, los animales se incorporan apenas terminada la extracción de orina, por lo que la apnea provocada es lo suficientemente leve como para no dañarlos. Los animales orinan rápidamente y se ahorra mucho tiempo en el trabajo de campo.

Tabla II. Ensayos fitoquímicos para diferentes órganos vegetales de Mulinum spinosum y tejido animal de corderos con y sin neneo. (Phytochemical assays for aerial parts of Mulinum spinosum and lambs tissues).

\begin{tabular}{|c|c|c|c|c|c|c|c|}
\hline \multirow{2}{*}{$\begin{array}{l}\text { Ensayos } \\
\text { fitoquímicos }\end{array}$} & \multirow[t]{2}{*}{ Flores } & \multirow[t]{2}{*}{ Frutos } & \multirow[t]{2}{*}{ Hojas } & \multicolumn{2}{|c|}{ Con neneo } & \multicolumn{2}{|c|}{ Sin neneo } \\
\hline & & & & carne & grasa & carne & grasa \\
\hline Taninos & - & + & + & - & - & - & - \\
\hline Mucílagos & - & - & - & \multicolumn{4}{|c|}{ No se realizó para muestras animales } \\
\hline Saponinas & + & + & - & - & - & - & - \\
\hline Compuestos reductores & + & + & + & + & + & $?$ & - \\
\hline Antracenósidos & + & ++ & ++ & - & - & - & - \\
\hline Flavonoides & ++ & + & - & - & - & - & - \\
\hline Cumarinas & - & - & - & \multicolumn{4}{|c|}{ No se realizó para muestras animales } \\
\hline Triterpenos/esteroles & + & ++ & - & - & - & - & - \\
\hline Antocianinas & + & + & - & - & - & - & - \\
\hline Alcaloides & - & - & - & \multicolumn{4}{|c|}{ No se realizó para muestras animales } \\
\hline
\end{tabular}

-: ausente; +: presente; ++: abundante; ?: sin concordancia entre repeticiones. 


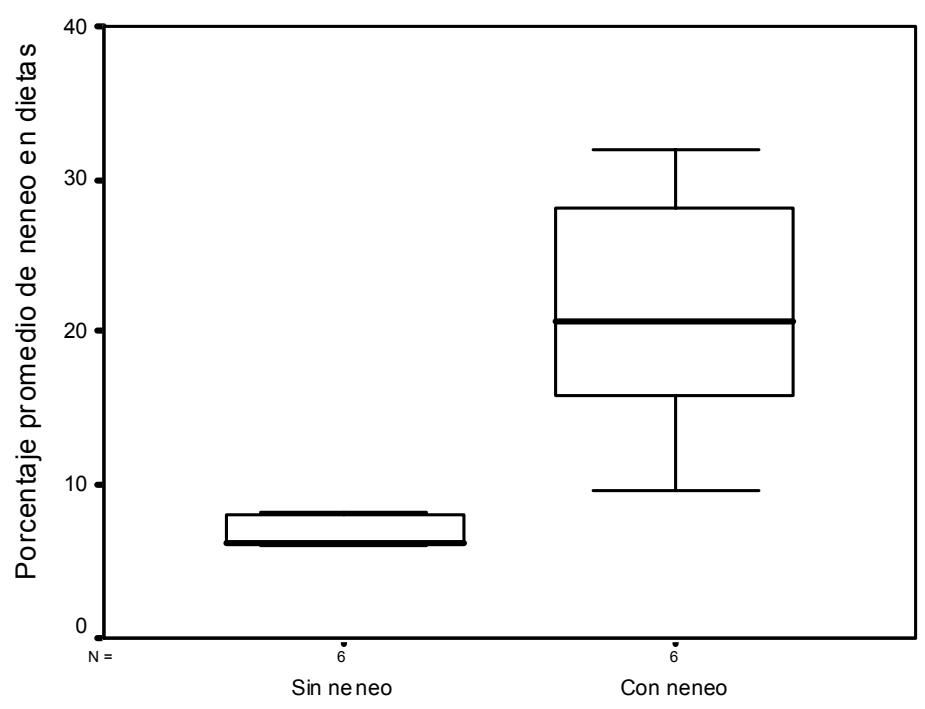

Figura 1. Porcentaje de Mulinum consumido en dieta de corderos con y sin neneo determinado mediante análisis microhistológico de heces. (Percentage of Mulinum in lamb diets determined through microhistological fecal analysis).

PROTOCOLO PARADETECTAR IN VIVOLA PRESENCIADEL NENEO ENRESES DE CORDERO

La técnica ensayada funcionó y exhibió resultados similares para las cantidades 1:10 y 1:100, mientras que la reducción 1:200 mostró problemas en los puntos 2 y $3 \mathrm{del}$ ensayo debido a la poca cantidad de muestra, específicamente en tratamientos de reflujo y extracción, respectivamente. De esta forma, se determina que la reducción 1:100 es la mínima funcional y se exponen sus resultados en la tabla $\mathbf{I V}$, mostrando las observaciones registradas para cada punto de este ensayo. Se puede ver allí que existe una diferencia notoria entre las observaciones registradas para orina de corderos con neneo respecto de aquellos sin neneo.

Las diferencias registradas en los ensayos para orina de corderos con y sin neneo (tabla IV) sumadas a pequeños ajustes empíricos experimentales, permitieron diseñar un protocolo para detectar el efecto del neneo en reses vivas (tabla $\mathbf{V}$ ). Este protocolo no está probado estadísticamente, por lo que queda a disposición de las pruebas que sean necesarias realizar por establecimientos ganaderos e investigadores para comprobar la fiabilidad de sus resultados.

\section{DISCUSIÓN}

\section{PRINCIPIOS QUÍMICOS DEL NENEO QUE AFEC- TAN LA CALIDAD DE LAS RESES}

Si bien sería interesante contar con un método de detección del neneo en carnes de frigorífico, se observa que el tratamiento de los tejidos animales ha resultado experimentalmente inestable, al menos con las técnicas experimentales ensayadas en este trabajo. Para estos propósitos, el único resultado que motiva una indagación futura es el ensayo para compuestos reductores en extractos de carne y grasa (tabla II).

El medio más apropiado para realizar los ensayos en el animal fue la orina debido a su estabilidad frente a diferentes reactivos y la constancia en la lectura de los resultados. No se encontraron datos respecto a la 
INCIDENCIA DE MULINUM SPINOSUM SOBRE LA CARNE OVINA

Tabla III. Ensayos fitoquímicos realizados en orina de corderos cony sin neneo. (Phytochemical assays on lamb urines with and without neneo).

\begin{tabular}{llcc}
\hline & Flavonoides & Saponinas & Triterpenos/esteroles \\
\hline $\begin{array}{l}\text { Orina de corderos sin neneo } \\
\text { Orina de corderos con neneo }\end{array}$ & $\begin{array}{l}\text { negativo } \\
\text { negativo }\end{array}$ & $\begin{array}{l}\text { positivo } \\
\text { positivo }\end{array}$ & $\begin{array}{c}\text { negativo } \\
\text { positivo }\end{array}$ \\
\hline
\end{tabular}

metabolización de terpenos en rumiantes, pero algunos estimados de flujo de renovación de ácidos grasos en ovejas indican que el tiempo de recambio en el tejido adiposo tiene un flujo de más de $1 \mathrm{~mol} /$ día (Emery, 1980). Esto permitiría seguir detectando los terpenos metabolizados en orina más allá de que un animal haya permanecido en encierro prolongado, o de un eventual cambio de dieta en los días previos al ensayo.

Aunque la carne no fue valorada sensorialmente y la metodología aplicada a muestras de carne y grasa no detectó resultados, la incidencia del neneo en la carne de los animales que lo ingieren es ampliamente respaldada por el conocimiento popular en toda la región estudiada.
Los compuestos encontrados en flores $\mathrm{y}$ frutos pero ausentes en hojas confirman las conclusiones de Ochoa et al. (2003) con la adición de antocianinas que, a pesar de esto, no fueron detectadas en tejidos animales con la técnica ensayada (tabla II). Los resultados exhibidos en la tabla III sugieren que la investigación sobre terpenos en orina de corderos con y sin neneo constituye un punto de partida consistente para identificar los principios químicos responsables del efecto del neneo en los animales. Cotejando con la bibliografía disponible sobre fitoquímica de $M$. spinosum (Chiessa y Montes, 1962; Nicoletti et al., 1996; Van Baren et al., 1997; Chiaramello et al., 2003), se infiere que la sustancia o el grupo de

Tabla IV. Observaciones registradas para cada punto de la técnica experimental aplicada a orina procedente de corderos con y sin neneo. (Recorded observations for each point of the experimental technique applied to lamb urine).

\begin{tabular}{|c|c|c|c|}
\hline \multirow[t]{2}{*}{ Corderos } & \multicolumn{3}{|c|}{ Observaciones para cada punto de la técnica experimental } \\
\hline & Punto 1 & Punto 2 & Punto 3 \\
\hline CONNENEO & $\begin{array}{l}\text { sin desprendimiento de gas } \\
\text { sin desprendimiento de gas } \\
\text { sin desprendimiento de gas } \\
\text { sin desprendimiento de gas } \\
\text { sin desprendimiento de gas } \\
\text { sin desprendimiento de gas }\end{array}$ & $\begin{array}{l}\text { marrón rojizo opaco } \\
\text { marrón rojizo opaco } \\
\text { marrón rojizo opaco } \\
\text { marrón rojizo opaco } \\
\text { marrón rojizo opaco } \\
\text { marrón rojizo opaco }\end{array}$ & $\begin{array}{l}\text { marrón } \\
\text { marrón } \\
\text { marrón } \\
\text { marrón claro } \\
\text { marrón } \\
\text { marrón }\end{array}$ \\
\hline SINNENEO & $\begin{array}{l}\text { desprendimiento de gas intenso } \\
\text { desprendimiento de gas intenso } \\
\text { desprendimiento de gas intenso } \\
\text { desprendimiento de gas intenso } \\
\text { desprendimiento de gas débil } \\
\text { desprendimiento de gas débil }\end{array}$ & $\begin{array}{l}\text { marrón rojizo traslúcido } \\
\text { marrón rojizo traslúcido } \\
\text { marrón rojizo traslúcido } \\
\text { marrón rojizo traslúcido } \\
\text { marrón rojizo traslúcido } \\
\text { marrón rojizo traslúcido }\end{array}$ & $\begin{array}{l}\text { amarillo } \\
\text { amarillo } \\
\text { amarillo } \\
\text { amarillo } \\
\text { amarillo } \\
\text { amarillo }\end{array}$ \\
\hline
\end{tabular}


sustancias responsable del efecto del neneo sobre las reses se corresponda con alguno de los terpenos encontrados por los distintos autores e incluso con una combinación de ellos. Si bien métodos como cromatografía gaseosa acoplada con espectrometría de masa (GC-MS) podrían resultar más adecuados para detectar varios de los compuestos estudiados, la complejidad y el costo de los mismos no satisfacen el requisito de sencillez del protocolo que se busca desarrollar.

$\mathrm{Si}$ bien es una observación empírica, cabe señalar que a los propósitos de este trabajo el método de extracción de orina resultó satisfactorio y ventajoso frente a la extracción directa de vejiga mediante penetración que suele utilizarse en estos casos. Algunas de ellas son que es más rápido, económico, el animal no sufre daños y cualquier productor puede realizarlo si cumple los límites de tiempo de apnea aconsejados. Además, no se ha encontrado ningún tipo de incompatibilidad con normativas éticas o de experimentación animal en la legislación revisada para Argentina y España.

\section{PROTOCOLOPARA DETECTAR IN VIVOLAPRE- SENCIA DEL NENEOEN RESESDE CORDERO}

La producción de carne es una de las opciones más promisorias para la diversificación de los sistemas ganaderos en Patagonia, tradicionalmente dedicados a la producción de fibras. Pero la variabilidad en la calidad de corderos y caprinos limita fuertemente su valor comercial (Giraudo y Taddeo, 2002) y la carencia de estudios sistemáticos sobre este tema impide implementar programas de desarrollo tecnológico sustentables para la producción de carne en la región.

No obstante, para avanzar en este sentido y poder evaluar la incidencia del neneo sobre la calidad de las reses, es imprescindible desarrollar previamente un método rápido y práctico que permita diagnosticar la contaminación de los animales con la planta. En este sentido, la perspectiva fitoquímica ofrece un camino posible para la investigación y en este marco el protocolo que se presenta para detectar la presencia de neneo sobre ovejas vivas (tabla V) cons-

Tabla $\boldsymbol{V}$. Protocolo propuesto para detectar la presencia de neneo sobre ovinos vivos. (Proposed protocol for detection of neneo in live sheep).

\begin{tabular}{|c|c|c|}
\hline Precauciones & Trabajo a campo & Metodología rápida en el laboratorio* \\
\hline $\begin{array}{l}\text { Trabajar primero } \\
\text { con las partes } 1 \text { y } 2 . \\
\text { Ventilar bien y apa- } \\
\text { gar el fuego antes } \\
\text { de empezar la parte } \\
\text { 3. Tomar precaucio- } \\
\text { nes para evitar eva- } \\
\text { poración del éter } \\
\text { (trabajar rápido, } \\
\text { reactivo frío, entre } \\
\text { otras). No tomar } \\
\text { contacto físico o } \\
\text { respiratorio con los } \\
\text { ácidos o el éter }\end{array}$ & $\begin{array}{l}\text { Se extraen mues- } \\
\text { tras de orina de } \\
\text { cada res mediante } \\
\text { la apnea del animal } \\
\text { hasta obtener la } \\
\text { muestra (método no } \\
\text { invasivo) }\end{array}$ & $\begin{array}{l}\text { Parte 1: Tomar } 0,5 \mathrm{ml} \text { de orina y agregar } 1 \text { gota de } \mathrm{HCl} \\
\text { (conc). (Desprendimiento de gas en animales } \mathrm{sin} \\
\text { neneo, sin desprendimiento en animales con neneo) } \\
\text { Parte } 2 \text { : Hervir hasta que quede color café (aprox. } 1 \\
\text { minuto). Adicionar } 0,2 \mathrm{ml} \text { de agua. (Marrón rojizo } \\
\text { opaco en animales con neneo, traslúcido en animales } \\
\text { sin neneo) } \\
\text { Parte } 3 \text { : Evaporar suavemente } 30 \text { segundos o hasta } \\
0,3 \mathrm{ml} \text { como máximo. A medida que se calienta debe } \\
\text { irse clarificando e intensificando. Extraer con } 1 \mathrm{ml} \text { de } \\
\text { éter, separar rápidamente la fase etérea y agregar } 0,5 \\
\text { ml de cloroformo y } 0,5 \mathrm{ml} \text { de anhídrido acético. Mezclar } \\
\text { y agregar } 3 \text { o } 4 \text { gotas de } \mathrm{H}_{2} \mathrm{SO}_{4} \text { (conc) } \\
\text { (La coloración final es marrón en animales con neneo } \\
\text { y amarillo en animales sin neneo) }\end{array}$ \\
\hline
\end{tabular}

${ }^{*}$ Cada parte debe realizarse como una continuación de la anterior. 


\section{INCIDENCIA DE MULINUM SPINOSUM SOBRE LA CARNE OVINA}

tituye una hipótesis tecnológica esperando a ser probada. De ser efectiva, permitiría un manejo ganadero que evite el sacrificio de animales contaminados y su consecuente pérdida económica (Ochoa y Seoane, 2007), a la vez que permitiría profundizar la investigación sobre este tema. Adicionalmente, el protocolo presentado y toda la metodología utilizada son sencillos y de bajo costo, lo que incluye como potenciales beneficiarios no sólo a los grandes productores, sino también a los pequeños y medianos.

\section{CONCLUSIÓN}

Se encontró que los compuestos químicos responsables del efecto del neneo en reses ovinas pertenecen al grupo de los terpenos presentes en $M$. spinosum.

\section{BIBLIOGRAFÍA}

Anchorena, J. 1978. Regiones ecológicas de Patagonia. Primer curso de Manejo de Pastizales. INTA EEA. Bariloche. Mimeo. 8 pp.

Bahamonde, N., Martin, S. and Sbriller, A. 1986. Diet of guanaco and red deer in Neuquen Province, Argentina. J. Range Manage., 39: 281-286.

Baldi, R., Sbriller, A., Elston, D. and Albon, S. 2004. High potential for competition between guanacos and sheep in Patagonia. J. Wildlife Manage., 68: 924-938.

Bonino, N., Bonvissuto, G., Sbriller, A. y Somlo, R. 1986. Hábitos alimentarios de los herbívoros en la zona central del área ecológica Sierras y Mesetas Occidentales de Patagonia. Rev. Argentina Prod. Anim., 6: 275-287.

Bonvissuto, G. y Somlo, R. 1998. Guías de condición para los campos naturales de "Precordillera" y "Sierras y Mesetas Occidentales" de Patagonia. INTA, EEA Bariloche. Comunicación Técnica Pastizales Naturales, 78: 1-35.

Chiaramello, A., Ardanaz, C., García, E. and Rossomando, P. 2003. Mulinane-type diterpenoids from Mulinum spinosum. Phytochemistry, 63: 883-886.

Chiessa, R. y Montes, A. 1962. Mulinum spinosum Persoon, neneo: estudio de la oleogomorresina
La orina es el medio más apropiado para identificar los metabolitos.

Se propone un protocolo para detectar el neneo en ovinos vivos. Éste queda a disposición para la puesta a prueba, con la intención de generar una herramienta que permita distinguir lotes de animales con neneo en el campo, evitando su sacrificio y consecuente pérdida económica.

\section{AGRADECIMIENTOS}

A Rafael Navarro, María Zimmerman, Carlos Sandoval y Matías Anfuso por su colaboración durante el trabajo de campo. Este trabajo se realizó en el marco del proyecto PID2001-00277 de la Agencia Nacional de Promoción Científica y Tecnológica de Argentina.

obtenida por exudado de plantas de la zona de Zapala en Neuquén. República Argentina. An. Soc. Cient. Argent., 173: 44-63.

Conover, W.J. 1980. Practical nonparametric statistics. John y Willey. New York. 597 pp.

Constance, L. 1988. Umbelliferae. En: Correa M.N.

(Ed.). Flora patagónica. Parte XXX. Colección Científica del INTA. Buenos Aires. pp. 310-379.

Dimitri, M.J. 1974. Pequeña flora ilustrada de los Parques Nacionales Andino Patagónicos. An. Parques Nacionales, 13: 65.

Domínguez, X. 1973. Métodos de investigación fitoquímica. Editorial Limusa, México. 281 pp.

Emery, R.S. 1980. Mobilization, turnover and disposition of adipose tissue lipids. In: Ruckebusch, Y. and P. Thivend (Eds.). Digestive physiology and metabolism in ruminants. Avi Publishing Co. Connecticut.

Farnsworth, N. 1966. Biological and phytochemical screening of plants. J. Pharmaceut. Sci., 55: 225-276.

Galende, G., Grigera, D. y Von Thüngen, J. 1998. Composición de la dieta del chinchillón (Lagidium viscacia, Chinchillidae) en el noroeste de Patagonia. Mastozoología Neotropical, 5: 125128.

Giraudo, C., Villagra, S. y Bidinost, F. 1999. Dife- 


\section{SEOANE, OCHOA, BORRELLI, SEVERINO, TADDEO, GIRAUDOY ANDRADE GAMBOA}

rentes estrategias para incrementar la productividad de los sistemas de ganadería ovina en precordillera y sierras y mesetas occidentales. Rev. Argentina. Prod. Anim., 19: 177-182.

Giraudo, C., Villagra, S., Bidinost, F., Gibbons, A., Abad, M., Uzal, F., Garramuño, J.M., Bustos, C., López, J., Carusso, G., Ababile, F. y Losardo, P. 2004. Parición en cobertizo para incrementar la producción de corderos. IDIA XXI, 7: 58-62.

Giraudo, C. y Taddeo, H. 2002. Estudio de los factores que afectan la tasa de crecimiento de corderos y chivitos. Informe Técnico INTA EEA. Bariloche. Provincia de Río Negro.

Holechek, J.L. 1982. Sample preparation techniques for microhistological analysis. J. Range Manage., 35: 541-542.

Holechek, J.L. and Gross, B. 1982. Evaluation of different calculation procedures for microhistological analysis. J. Range Manage., 35 721-723.

Latour, M.C. y Sbriller, A. 1981. Clave para la determinación de la dieta de herbívoros en e Noroeste de la Patagonia. Rev. Invest. Agropecu. 16: 109-157.

Monteith, N. 1970. Incremento de la producción ovina en la Patagonia. Informe técnico FAOINTA. Bariloche. 30 pp.

Montes, M. y Wilkomirsky, T. 1985. Medicina Tradicional Chilena, $2^{\mathrm{a}}$ edición. Editorial de la Universidad de Concepción. Concepción. Chile. $201 \mathrm{pp}$.

Nicoletti, M., Di Fabio, A., D'Andres, A., Salvatore, G., Van Baren, C. and Coussio, J.D. 1996. Diterpenoid acids from Mulinum spinosum. Phytochemistry, 43: 1065-1067.

Ochoa, J. y Seoane, N. 2007. Determinación de la familia de metabolitos secundarios responsable del sabor adquirido por corderos debido a la ingesta de Mulinum spinosum (Cav.) Pers. (Apiaceae) en Patagonia. III Jornadas Naciona- les de Flora Nativa y IV Encuentro de Cactáceas Córdoba. Argentina, pp. 140.

Ochoa, J., Seoane, N. y Bidinost, F. 2003. El problema del neneo en Patagonia: una aproximación fitoquímica. Bol. Soc. Argent. Bot., 38: 213.

Prache, S. 2007. Developing a diet authentication system from the composition of milk and meat in sheep: a review. J. Agric. Sci., 145: 435-444.

Sánchez, M., Sanjuán, A. y Akl, G. 2001. El distintivo de calidad como indicador de seguridad alimenticia en carne de vacuno y cordero. Econ. Agr. Recurs. Nat., 1: 77-94.

Sharapin, N. 2000. Fundamentos de tecnología de productos fitoterapéuticos. Convenio Andrés Bello. Programa Interamericano de Ciencia y Tecnología para el desarrollo. Colombia. pp. 195-202.

Somlo, R., Campbell, G. and Sbriller, A. 1981. Study of the dietary habits of Angora goats in rangelands of Patagonia. Symposium International Nutrition et Systemes d'Alimentation de la chevre. ITOVIC-INRA. Tours. France. I: 525244

Soriano, A. 1949. Pastoreo en la parte semidesértica del Chubut. IDIA, 2: 8-14.

Van Baren, C., Di Leo, P., Coussio, J.D., Bandoni, A., Mizrahi, I. and Juárez, M. 1997. Composition of essential oil of "neneo", Mulinum spinosum (Cav.) Pers. (Umbelliferae) from Chubut, Argentine. Int. Joint Symp: Chemistry, Biological y Pharmacological properties of medicinal plants from Americas. Panamá.

Williams, O.B. 1969. An improved technique for identification of plant fragments in herbivore feces. J. Range Manage., 21: 264-265.

Wood, J.D., Enser, M., Fisher, A.V., Nute, G.R., Richardson, R.I. and Sheard, P.R. 1999. Manipulating meat quality and composition. $P$. Nutr. Soc., 58: 363-370. 